\title{
TMF and glycitin act synergistically on keratinocytes and fibroblasts to promote wound healing and anti- scarring activity
}

\author{
Ga Young Seo ${ }^{1}$, Yoongho $\mathrm{Lim}^{2}$, Dongsoo $\mathrm{Koh}^{3}$, Jung Sik Huh ${ }^{4}$, Changlim Hyun ${ }^{5}$, Young Mee Kim ${ }^{1}$ \\ and Moonjae Cho ${ }^{1,6}$
}

\begin{abstract}
Keratinocyte-fibroblast interactions are critical for skin repair after injury. During the proliferative phase of wound healing, proliferation, migration and differentiation of these cells are the major mechanisms leading to tissue remodeling. We have previously reported that glycitin, a major soy isoflavone, stimulates dermal fibroblast proliferation; and the phytochemical, 4',6,7-trimethoxyisoflavone (TMF), induces migration of HaCaT keratinocyte cells. We therefore investigated whether these compounds display synergistic effects on skin cells during wound healing in vitro and in vivo. Co-treatment with TMF and glycitin synergistically promotes the proliferation and migration of both keratinocytes and dermal fibroblasts, with a 1:1 ratio of these compounds showing the greatest efficacy in our co-culture system. This keratinocyte-fibroblast interaction occurred via the secretion of TGF- $\beta$, and the induction of differentiation and proliferation was confirmed in both indirect and direct co-culture assays. In an excisional and burn wound animal model, mice treated with a 1:1 ratio of TMF and glycitin showed faster wound closure, regeneration and scar reduction than even the positive control drug. These data indicate that two isoflavones, TMF and glycitin, act synergistically to promote wound healing and anti-scarring and could potentially be developed together as a
\end{abstract} bioactive therapeutic for wound treatment.

Experimental \& Molecular Medicine (2017) 49, e302; doi:10.1038/emm.2016.167; published online 17 March 2017

\section{INTRODUCTION}

Flavonoids are a class of compounds comprised of more than 4000 phenylbenzopyrones, which are widely produced in edible plants. These have been reported to have diverse pharmacological activities, including antioxidative, antinflammatory and anticancer properties. ${ }^{1-3}$ Among them, the soy isoflavones in particular, including genistein, daidzein and glycitein, have been found to exhibit chemo-preventive, cardio-protective and anti-osteoporosis effects. ${ }^{4-6}$

In our previous studies, we found that the soy isoflavone, glycitin (4'-hydroxy-6-methoxyisoflavone-7-D-glucoside), protects skin from photoaging by increasing expression of collagen I in UV-exposed human dermal fibroblasts. ${ }^{7}$ This compound can also promote cell viability and migration via the transforming growth factor-beta (TGF- $\beta$ ) pathway. ${ }^{8}$ Another compound, TMF (4',6,7-trimethoxyisoflavone), which is a chemically transformed product of an amphiisoflavone isolated from the roots of the medicinal plant,
Amphimas pterocarpoides, ${ }^{9}$ was found to enhance migration of HaCaT keratinocytes through activation of NADPH oxidase 2 (NOX2). ${ }^{10}$

Cutaneous wound repair is an intricate process that includes three phases: inflammation, proliferation and remodeling. During the proliferation phase, various types of cells migrate to the wound site. ${ }^{11}$ Keratinocytes, the most prevalent cell type in the epidermis, and fibroblasts, the predominant cell type in dermis, have important roles in the process of skin repair after injury, and their interactions are critical for this process. ${ }^{12}$ Keratinocytes secrete both platelet-derived growth factor (PDGF) and TGF- $\beta$, which function to stimulate dermal fibroblasts. ${ }^{13}$ Activated fibroblasts then migrate into the wound site and initiate the production of extracellular matrix (ECM) components, such as collagen, gelatin and fibronectin. ${ }^{14}$ For example, in a study by Shephard et al., ${ }^{15}$ TGF- $\beta$ produced from keratinocytes promotes the differentiation of fibroblasts and induces

\footnotetext{
${ }^{1}$ Department of Biochemistry School of Medicine, Jeju National University, Jeju, Korea; ${ }^{2}$ Division of Bioscience and Biotechnology, Konkuk University, Seoul, Korea; ${ }^{3}$ Department of Applied Chemistry, Dongduk Women's University, Seoul, Korea; ${ }^{4}$ Department of Urology, School of Medicine, Jeju National University, Jeju, Korea; ${ }^{5}$ Department of Pathology, School of Medicine, Jeju National University, Jeju, Korea and ${ }^{6}$ Institute of Medical Science, Jeju National University, Jeju, Korea

Correspondence: Dr YM Kim or Professor M Cho, Department of Biochemistry School of Medicine, Jeju National University, 102 Jejudaehak-ro, Jeju-si Korea. E-mail: biochem310@jejunu.ac.kr or moonjcho@jejunu.ac.kr
}

Received 30 May 2016; revised 27 September 2016; accepted 31 October 2016 
expression of alpha-SMA (alpha-smooth muscle actin) in myofibroblast cells.

During the final phase of wound healing, known as remodeling, processes such as re-epithelialization, angiogenesis and fibrosis, are stopped, ${ }^{16}$ and collagen synthesis is increased; this is then deposited on the wound site to form a scar. ${ }^{17}$ Over time, collagens are rearranged to form a cross stripe pattern, which is a feature of normal skin, and the scar becomes fainter. Various compounds have been shown to promote this process; clodronate liposomes, for example, decrease scar formation by reducing expression of both collagen and TGF- $\beta .^{18}$

A number of studies have utilized several types of co-culture systems to study the interactions between epidermal and dermal cells during wound healing. Wang et al. ${ }^{19}$ reported that co-culture in a transwell system with human fetal epidermal keratinocytes could promote the proliferation and migration of human fetal and adult dermal fibroblasts. In this model, both migration and proliferation were enhanced through the induction of cyclin B1, phospho-CDK1, phosphoAKT, C-X-C chemokine receptor 4 (CXCR4) and matrix metalloproteinases (MMPs). Shephard et al. ${ }^{15}$ further demonstrated this effect with keratinocytes and fibroblasts that were simultaneously incubated on cell culture dishes in direct contact with one another. These, and numerous other recent studies, have highlighted the importance of synergistic interaction and communication between these cell types.

Here, we show that treatment with a combination of TMF and glycitin promotes wound repair processes, both in cell culture and in vivo, and this activity is most pronounced when the compounds are mixed in a 1:1 ratio. The effects of the combined glycitin-TMF treatment on keratinocytes and fibroblasts were confirmed in both an indirect and direct-contact culture system, and the combined synergistic activity was mediated, at least in part, by elevated levels of secreted TGF- $\beta$. To confirm these results in vivo, we tested the effect of treatment with a 1:1 mixture of glycitin and TMF using mouse excisional and burn wound models. Our results suggest that co-treatment with TMF and glycitin accelerates skin regeneration and reduces scar formation after injury.

\section{MATERIALS AND METHODS}

\section{Materials}

4'-Hydroxy-6-methoxyisoflavone-7-D-glucoside (glycitin) and TMF were purchased from Indofine Chemical (Hillsborough, NJ, USA). These were used without further purification, and purities were determined using high-performance liquid chromatography. ${ }^{2}$ The TMF and glycitin powder was dissolved in DMSO. For in vivo experiments, butylene glycol was used as a carrier to treat the wound site of mice.

\section{Cell culture}

Primary human dermal fibroblasts and the human keratinocyte cell line $(\mathrm{HaCaT})$ were stabilized and cultured in Dulbecco's Modified Eagle Medium (DMEM, Gibco, Carlsbad, CA, USA) that was supplemented with $10 \%$ fetal bovine serum (FBS, Omega, Singapore,
Singapore) and $1 \%$ penicillin/streptomycin (PAA). Cells were incubated in a humidified atmosphere at $37^{\circ} \mathrm{C}$ in $5 \% \mathrm{CO}_{2}$.

\section{MTT (3-(4,5-dimethyltiazol-2yl)-2,5-diphenyltetrazolium bromide) assay}

HaCaT keratinocyte cells were seeded in 96-well plates at a density of $2 \times 10^{3}$ cell/well. After $24 \mathrm{~h}$, cells were treated with one of the following: dimethyl sulfoxide (DMSO), glycitin:TMF $=1: 1$ $(10 \mu \mathrm{M}: 10 \mu \mathrm{M})$, glycitin:TMF $=1: 2(6.7 \mu \mathrm{M}: 13.3 \mu \mathrm{M})$, glycitin:TMF $=2: 1$ $(13.3 \mu \mathrm{M}: 6.7 \mu \mathrm{M})$, or conditioned media from fibroblasts treated with the above conditions. MTT solution (Sigma, St Louis, MO, USA) was then added to each well, and cells were incubated for an additional $4 \mathrm{~h}$. Subsequently, the medium was removed and replaced with $150 \mu \mathrm{l} \mathrm{DMSO}$, and plates were incubated for $30 \mathrm{~min}$ with shaking to dissolve the precipitate. Absorbance was measured at $570 \mathrm{~nm}$ using a spectrophotometer. Identical experiments were performed with primary human dermal fibroblast cells using the glycitin and TMF ratios specified above and conditioned media from $\mathrm{HaCaT}$ cells treated with same conditions.

\section{Scratch wound healing assay}

HaCaT keratinocyte cells were seeded in 48 -well plates at a density of $3 \times 10^{4}$ cells per well for $24 \mathrm{~h}$. A scratch was made on the monolayer by drawing a sterile pipette tip across the well, and the culture medium was supplemented with DMSO, glycitin:TMF $=1: 1$ $(10 \mu \mathrm{M}: 10 \mu \mathrm{M})$, glycitin:TMF $=1: 2(6.7 \mu \mathrm{M}: 13.3 \mu \mathrm{M})$, glycitin:TMF $=2: 1$ $(13.3 \mu \mathrm{M}: 6.7 \mu \mathrm{M})$ or conditioned media from fibroblasts treated with the same conditions. At time 0 and $24 \mathrm{~h}$ post treatment, wound closure was captured at $\times 40$ magnification using an Olympus IX70 (Tokyo, Japan) microscope equipped with a digital camera. Distance was measured using the Image J Software (Lviv, Ukraine), and the difference between the initial and final width of the scratch was calculated.

\section{Invasion assay}

For single culture assays, HaCaT cells or fibroblasts $\left(7 \times 10^{4}\right.$ cells per well) were seeded in the insert of a 12-well invasion assay kit (SPL), and the bottom portion was filled with media. For co-culture assays, one cell type was seeded in the insert, and the other type was seeded in the bottom, using equal numbers of each (for example, HaCaT cells in the insert and fibroblasts in the bottom and vice versa). The membrane allows the exchange of media during incubation. After $24 \mathrm{~h}$, serum-free media was added to the insert to allow for chemotaxis, and cells in both the insert and bottom were treated with either DMSO control or G:T $=1: 1$ for $48 \mathrm{~h}$. Cells on the upper side of the insert were then removed using a cotton swab, and cells on the lower side of the insert were fixed with $4 \%$ formaldehyde. After washing with PBS, invaded cells were stained with a $1 \%$ crystal violet solution, and photographs were acquired at $\times 4$ magnification using an Olympus IX70 microscope. Invasive ability was measured using the Image J program.

\section{Reverse transcription polymerase chain reaction (RT-PCR)} TRIzol reagent (MRC) was used to isolate total cellular RNA according to the manufacturer's instructions. The primer sequences were as follows: forward $5^{\prime}$-GTTCAAGCAGAGTAACACAGC- $3^{\prime}$ and reverse $5^{\prime}$-GTATTTCTGGTACAGCTCCACG-3' for TGF- $\beta$; forward 5'-GAAGGTGAAGGTCGGAGTC- ${ }^{\prime}$ and reverse $5^{\prime}$-GAAGATGGTGA TGGGATTTC- $3^{\prime}$ for GAPDH. The results were analyzed using Image J program. 


\section{In vivo excision wound model}

Six-week-old male ICR mice ( $n=6$ for each group) were chosen for the experiment. All procedures were approved by the Animal Care and Use Committee Jeju National University (permission number 2015-0033). Before wounding, the fur was removed with an electronic hair clipper and removal cream. Dermal wounds were then placed on the middle of the back using a 5-mm punch instrument. Wounds of mice in the experimental group were treated daily with $200 \mu \mathrm{l}$ of a 1:1 mixture of glycitin and TMF $(200 \mu \mathrm{M}: 200 \mu \mathrm{M})$ dissolved with butylene glycol for 14 days. Madecassol (Dongkook pharmaceutical, Seoul, Republic of Korea) and Fucidin (DongWha pharm, Seoul, Republic of Korea) were utilized as positive controls and applied to wound sites at the same concentration and for the same duration of time.

The wounds were visualized every 2 days, and the rate of wound closure was calculated as relative percentage of the original wound area, using the image J program. At 14 days post wound, skin tissue was isolated and fixed using a $4 \%$ formaldehyde solution. Paraffinembedded tissues were cut into $3-\mathrm{mm}$ sections and stained using hematoxylin-eosin and Masson's trichrome.

\section{In vivo burn wound model}

Eight-week-old female C57BL/6 mice ( $n=5$ for each group) were chosen for this experiment. The fur was removed with an electronic hair clipper and removal cream, and burn wounds were placed on the rump using a red-hot iron nail $(7 \mathrm{~mm}$ in diameter). Burns in the experimental group were then treated with $200 \mu \mathrm{l}$ of TMF $(200 \mu \mathrm{M})$ or $200 \mu \mathrm{l}$ of a 1:1 mixture of TMF and glycitin $(200 \mu \mathrm{M}: 200 \mu \mathrm{M})$ daily for 8 weeks; the control group was treated with the same amount of DMSO. Post treatment wounded skin were collected from mice at each time points and fixed in $4 \%$ formaldehyde. Paraffin-embedded tissues were then cut into 3-mm sections, and all sections were stained using hematoxylin-eosin and Masson's trichrome.

\section{Western blot}

HaCaT and fibroblast cells were seeded $\left(1 \times 10^{5}\right.$ each $)$ on $100 \mathrm{~mm}$ cell culture dishes and incubated for $24 \mathrm{~h}$. These were treated with 10-20 $\mu \mathrm{l}$ of glycitin, 10-20 $\mu \mathrm{l}$ of TMF, or the following combinations of glycitin and TMF: glycitin:TMF $=1: 1 \quad(10 \mu \mathrm{M}: 10 \mu \mathrm{M})$, glycitin: $\mathrm{TMF}=1: 2 \quad(6.7 \mu \mathrm{M}: 13.3 \mu \mathrm{M})$ and glycitin:TMF $=2: 1 \quad(13.3 \mu \mathrm{M}: 6.7 \mu \mathrm{M})$ for $72 \mathrm{~h}$. Total protein was extracted from treated cells using RIPA buffer, and protein concentration was determined using the BCA Protein Assay Kit (Thermo Scientific, Waltham, MA, USA). To investigate the expression of secreted factors, conditioned media was harvested and concentrated using amicon centrifugal filter (Merck Milipore, Billerica, MA, USA), and total protein concentration was measured using the Bradford assay. Skin tissue isolated from mouse wound sites was lysed using T-PER Tissue Protein Extraction Reagent (Thermo Scientific) and homogenized. Following centrifugation (14 000 r.p.m., $4{ }^{\circ} \mathrm{C}, 20 \mathrm{~min}$ ), supernatants were collected and used for western blot analysis.

Equal amounts of protein $(\sim 30 \mu \mathrm{g}$ per lane) were analyzed from each sample by resolving with $10 \%$ sodium dodecyl sulfatepolyacrylamide gel electrophoresis. Gel contents were transferred to PVDF membranes, and these were blocked in 5\% non-fat dry milk with Tris-buffered saline Tween 20 (TBST) buffer, followed by incubation with primary antibodies at $4{ }^{\circ} \mathrm{C}$ overnight. Cytokeratin 10 (sc-53252, 2nd Ab:rabbit), Cytokeratin 14 (sc-17104, 2nd Ab:goat) and GAPDH (sc-25778, 2nd Ab:rabbit), antibodies were purchased from Santa Cruz Biotechnology (Dallas, TX, USA); S100A4 (ab27957, 2nd Ab:rabbit) antibody was purchased from ABcam (Cambridge,
UK); TGF- $\beta$ (\#3711, 2nd Ab:rabbit) antibody was purchased from Cell Signaling Technology (Danvers, MA, USA); and $\beta$-actin (A5316, 2nd Ab:mouse) antibody was purchased from Sigma-Aldrich. We used anti-mouse (K0211589, KOMABIOTECH, Seoul, Korea), anti-rabbit (K021178, KOMABIOTECH) and anti-goat (AP1079P, Millipore). Proteins were detected using chemiluminescent regeant, ECL solution (W6002, Biosesang, Seoul, Korea).

\section{RESULTS}

We previously reported that glycitin (4'-hydroxy-6-methoxyisoflavone-7-D-glucose, Figure 1a) induces the proliferation and migration of fibroblasts, ${ }^{1,9}$ whereas TMF (Figure 1b) promotes HaCaT keratinocyte migration, but not proliferation. ${ }^{2}$ In an excisional wound experiment, we found that TMF accelerates re-epithelialization, and appendages were formed along the epidermis at 15 days after the wounding event. By contrast, groups receiving other treatments had a thick epidermis and less differentiating appendages than those treated with TMF (Supplementary Data 1). Because wound closure involves closure of the epidermis, known as re-epithelialization, as well as dermal closure, which requires both fibroblast cells and collagens, we hypothesized that a mixture of glycitin and TMF may enhance the wound healing process by synergistically stimulating cells in both the epidermis and dermis.

\section{Treatment with a 1:1 ratio of glycitin and TMF most effectively stimulates proliferation, migration and invasion ability in an indirect-co-culture system}

To determine the effect of treatment with mixture of glycitin and TMF on keratinocytes and fibroblast cells, we mixed these compounds at various ratios: $\mathrm{G}: \mathrm{T}=1: 1, \mathrm{G}: \mathrm{T}=1: 2$ and $\mathrm{G}: \mathrm{T}=2: 1$ (G: glycitin, T: TMF). We then measured the proliferation and migration of human dermal fibroblast cells that were either treated with the different combinations of the two compounds or incubated with conditioned media from HaCaT keratinocyte cells treated with the same stimuli. We observed increased proliferation of fibroblasts treated with $\mathrm{G}: \mathrm{T}=1: 1,1: 2$ and 2:1but did not see the same effect in cells treated with other combinations of glycitin and TMF or the HaCaT cell-conditioned media (Figure 2a). Fibroblast migration was increased in all G:T treated groups, whereas treatment with conditioned media did not increase migration. We note that the migratory distance of fibroblasts treated with conditioned media actually decreased as compared with the untreated control group (Figure 2b). This suggests
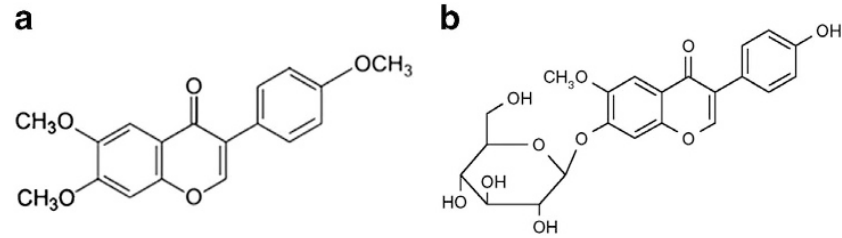

Figure 1 The chemical structure of TMF and glycitin. (a) TMF (4',6,7-trimethoxyisoflavone). (b) Glycitin (4'-hydroxy-6methoxyisoflavone-7-D-glucoside). TMF, 4',6,7-trimethoxyisoflavone. 
that treatment with glycitin and TMF induces HaCaT cell to produce factors that inhibit fibroblast migration.

We next assessed the effect of glycitin and TMF treatment on $\mathrm{HaCaT}$ keratinocytes and observed both increased proliferation and migration distance in cells treated with $\mathrm{G}: \mathrm{T}=1: 1$ (Figure $2 \mathrm{c}$ and $\mathrm{d}$ ). This synergistic effect was also present when HeCaT cells were incubated with conditioned media from fibroblast cells treated with $\mathrm{G}: \mathrm{T}=1: 1$

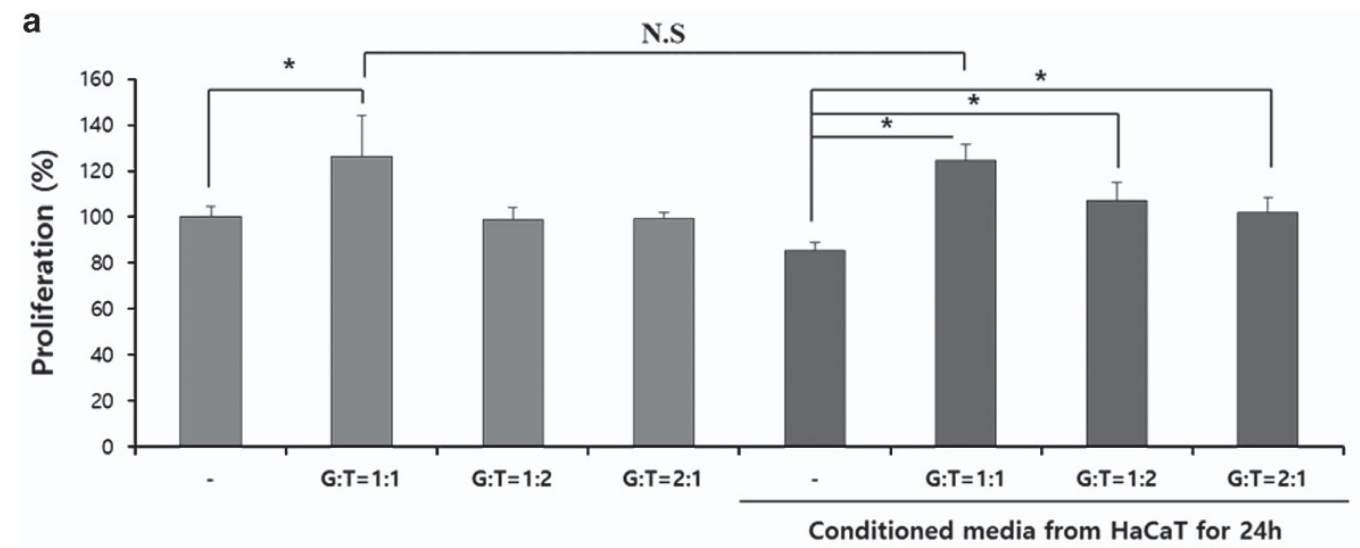

b
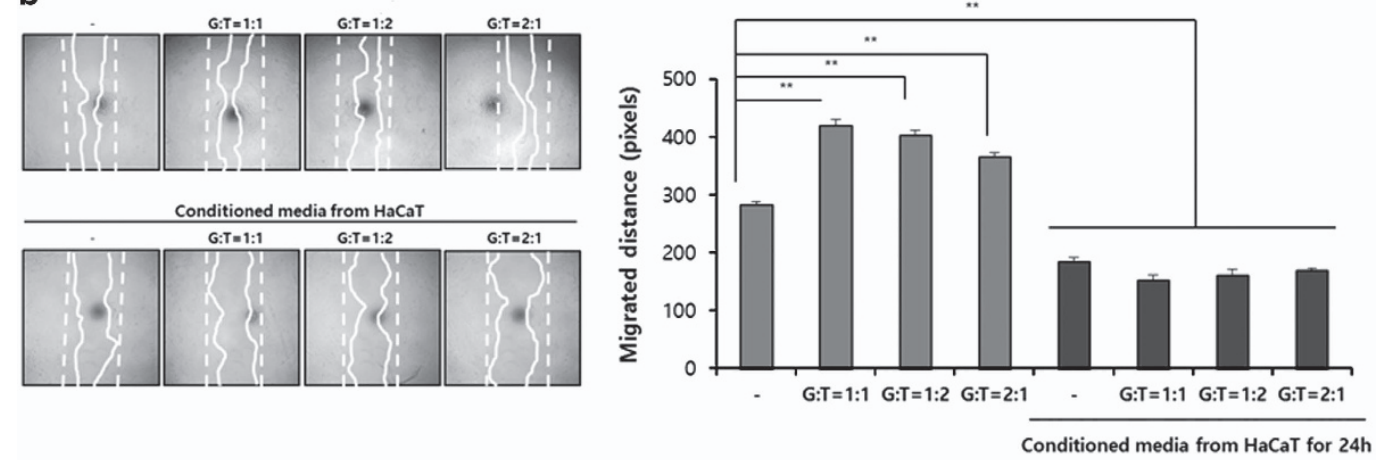

C

**

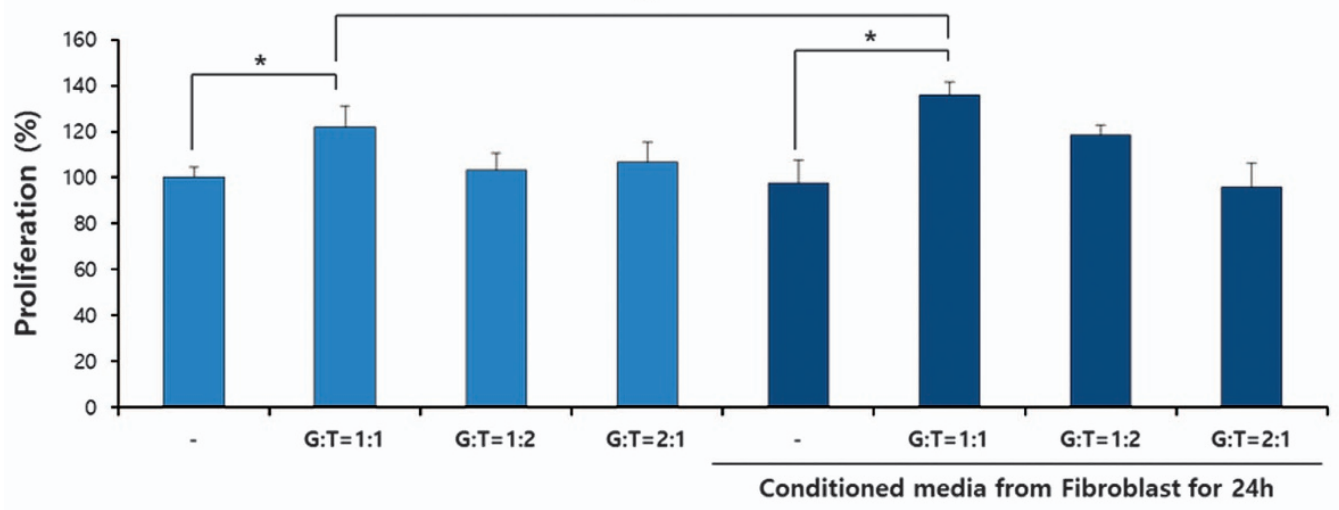

d
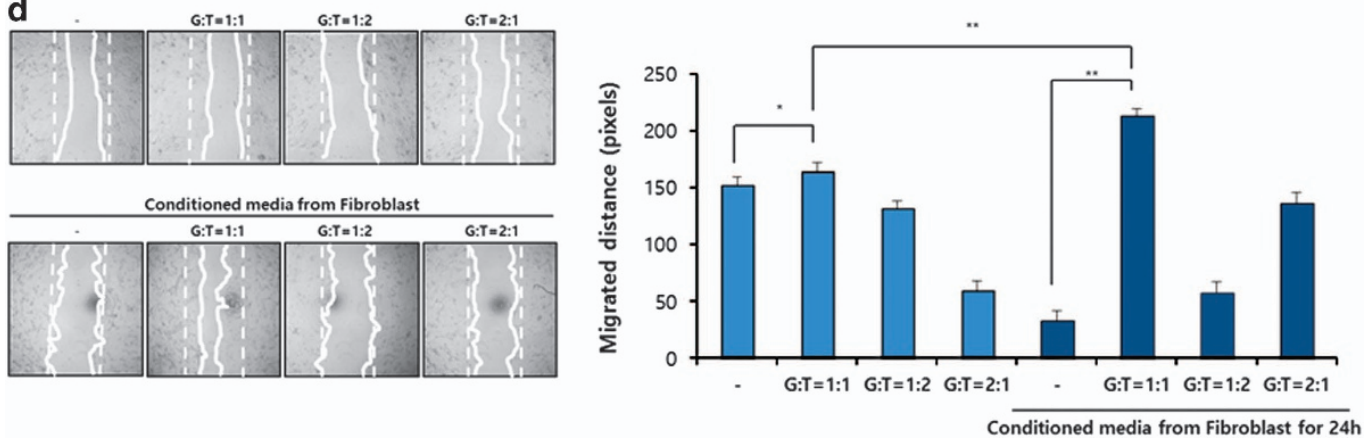
(Figure $2 \mathrm{c}$ and $\mathrm{d}$ ). These data suggest that a 1:1 ratio of glycitin and TMF is most effective at inducing the proliferation and migration of both dermal fibroblasts and keratinocytes. Further, our results imply that these two types of skin cells can communicate with one another by secreting unidentified factors when stimulated with a mixture of glycitin and TMF.

\section{A 1:1 mixture of glycitin and TMF promotes invasion by stimulating keratinocyte-fibroblast interaction}

We next used transwell plates, which have $8 \mu \mathrm{m}$ pore polycarbonate membrane inserts and allow media to be shared simultaneously between different cell types, to assess the effect of glycitin and TMF on the 3D-invasion of fibroblasts and keratinocytes. In single culture conditions, HaCaT keratinocytes and fibroblasts were seeded alone and treated with DMSO control or glycitin:TMF $=1: 1$ for $48 \mathrm{~h}$ (Figure $3 \mathrm{a}$ and $\mathrm{c}$, left diagram). For co-culture experiments, cells were incubated together, with one cell type in each half of the plate, and treated with the same stimuli (Figure $3 \mathrm{a}$ and $\mathrm{c}$, right diagram). In contrast to what was observed in our migration assays, we found that treatment of $\mathrm{HaCaT}$ and fibroblast cells individually with $\mathrm{G}: \mathrm{T}=1: 1$ did not significantly affect invasion (Figure $3 \mathrm{~b}$ and $\mathrm{d}$, left). However, we did measure a significant increase in invasion for both the co-cultured fibroblast and keratinocyte cells stimulated with G:T $=1: 1$, as compared with controls (Figure $3 \mathrm{~b}$ and $\mathrm{d}$, right).

It should be noted that the co-culture system only allows the sharing of factors secreted through the media, whereas in tissues, fibroblasts and keratinocytes contact one another directly. We therefore cultured fibroblasts and HaCaT keratinocytes in the same insert plate to allow for direct contact, as well as media sharing (Figure 3e). In this system, to distinguish these cell types, we developed a mCherry-labeled $\mathrm{HaCaT}$ cell line. Co-cultured cells were treated with the glycitin and TMF, and invasion was measured by fluorescence microscopy, for keratinocytes, and crystal violet staining, for total cells. We found that treatment with a mixture of glycitin and TMF enhanced the invasion of both cell types (Figure 3f). As the cell-to-cell contact did not show enhanced migration after the media change, we concluded that cell-to-cell contact is not a main factor in the synergistic effect of TMF and glycitin on wound healing.

\section{A combination of glycitin and TMF induces differentiation of keratinocytes and fibroblasts and increases secretion of TGF- $\beta$}

Because treatment with glycitin and TMF can synergistically promote migration and invasion of $\mathrm{HaCaT}$ cells in a co-culture system, we next to tried to elucidate the mechanism underlying this process. After injury, to restore epidermal barrier function, the epidermis begins to proliferate in the basal layer, followed by differentiation in the spinous and granular layers. Keratin 5 (KRT5)/Keratin 14 (KRT14) are often used as markers for proliferation in the basal layer, and Keratin 1 (KRT1)/Keratin 10 (KRT10)/involucrin are commonly utilized to distinguish differentiated suprabasal layers. Keratin expression induces a switch to re-epithelialization. We therefore performed direct-contact co-culture assays with fibroblast and $\mathrm{HeCaT}$ cells treated with either glycitin, TMF, or a 1:1 mixture of the two compounds for $24 \mathrm{~h}$ and measured expression of these marker proteins by western blot analysis (Figure 4 ). We found that low-dose glycitin treatment could induce differentiation of keratinocytes, and in high doses, the expression of keratinocyte proliferation markers, KRT14, were increased (Figure 4a). Treatment with TMF alone mainly induced proliferation of keratinocytes, as evidenced by our previous research. ${ }^{2}$ Interestingly, treatment of keratinocytes with a 1:1 mixture of glycitin and TMF treatment increased differentiation, but decreased proliferation, as compared with TMF treatment alone (Figure 4a).

In addition to the epidermis, differentiation in the dermis functions to contract and close the wound region, and fibroblasts in particular, which are the predominant cell type in the dermis, are activated to form myofibroblasts. Fibroblastspecific protein 1 (FSP1), a member of the S100 superfamily, is involved in inflammation, cell growth, cell cycle and differentiation of various different types of fibroblasts, including those in the lung, liver, skin and heart. We found that in direct co-culture assays, expression of FSP1 showed a 16-fold increase in fibroblasts treated with a 1:1 ratio of glycitin and TMF (Figure 4a).

TGF- $\beta$ has important pleiotypic roles and enhances the migration and differentiation of keratinocytes and fibroblasts throughout the proliferation phase of wound healing. Using a scratch wound healing assay in HaCaT keratinocytes or fibroblasts, we determined that treatment with TGF- $\beta$ ( 5 and $10 \mathrm{ng} \mathrm{ml}^{-1}$ ) as well as treatment with TMF and glycitin increases the migratory ability of the cells

Figure 2 Glycitin and TMF act synergistically to promote the proliferation and migration of HaCaT keratinocytes and human dermal fibroblasts in culture. (a) Proliferation of dermal fibroblasts treated with either glycitin and TMF, mixed in varying ratios or conditioned media from HaCaT keratinocytes treated with same conditions for $24 \mathrm{~h}$, as measured by MTT assay. (b) Scratch wound healing assay with dermal fibroblasts treated as described in a for $24 \mathrm{~h}$. Migration distance was measured using the Image J program. (c) Proliferation of $\mathrm{HaCaT}$ keratinocytes treated with either glycitin and TMF, mixed in varying ratios or conditioned media from dermal fibroblasts treated with the same conditions for $24 \mathrm{~h}$, as measured by MTT assay. (d) Scratch wound healing assay with HaCaT keratinocytes treated as described in c for $24 \mathrm{~h}$. Migration distance was measured using the ImageJ program. ${ }^{*} P<0.05$ as compared with control, ${ }^{* *} P<0.001$ as compared with control, G: glycitin, T: TMF. TMF, 4',6,7-trimethoxyisoflavone. 


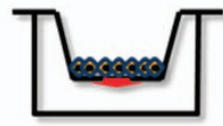

Insert : HaCaT

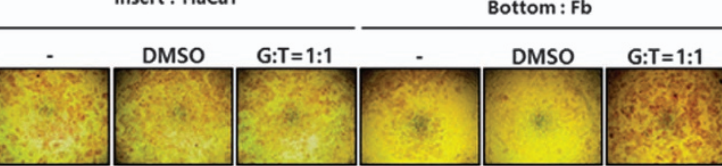

b

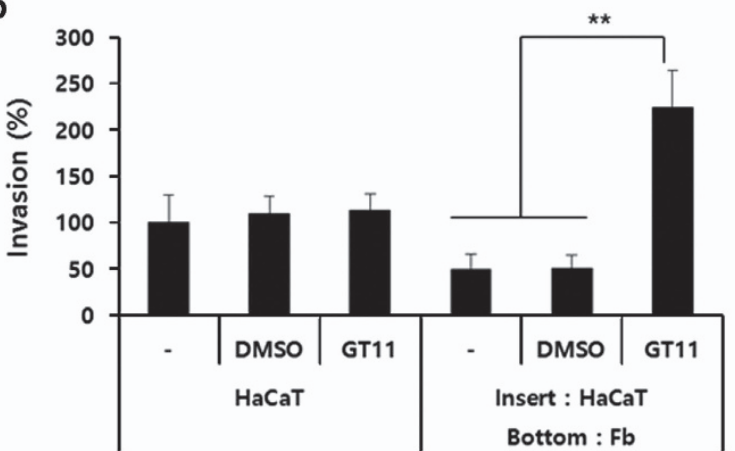

C

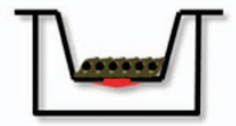

Insert : Fb

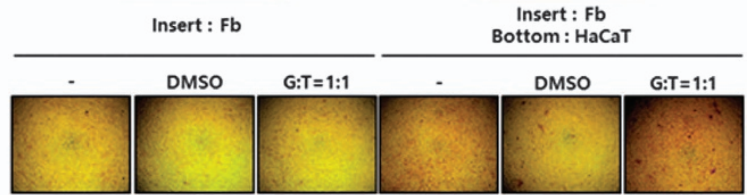

d

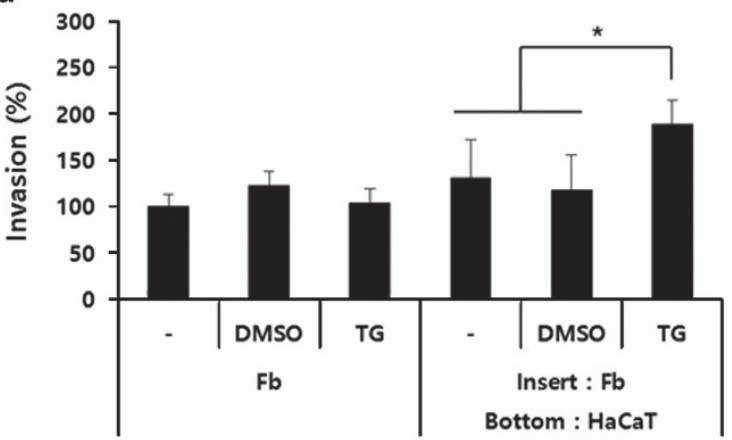

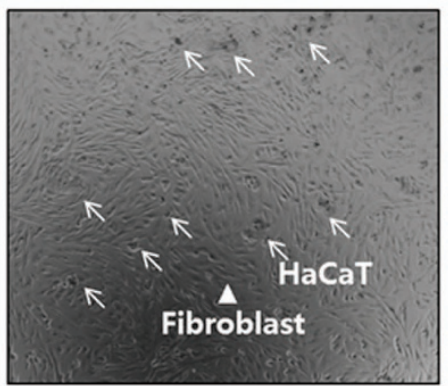
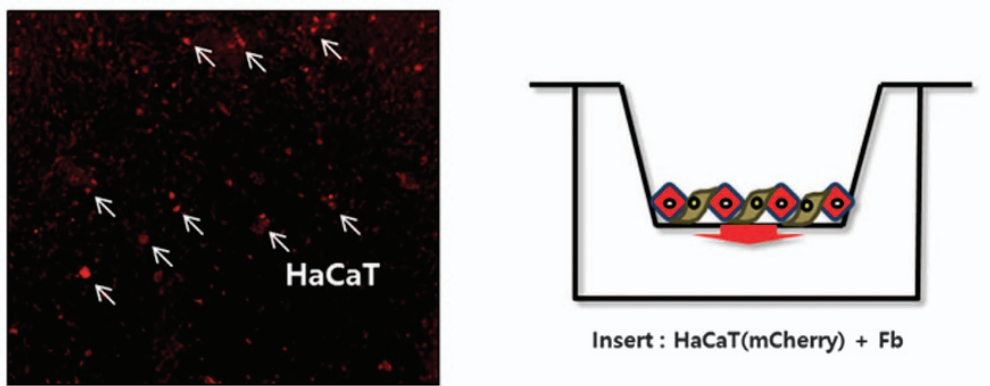

f
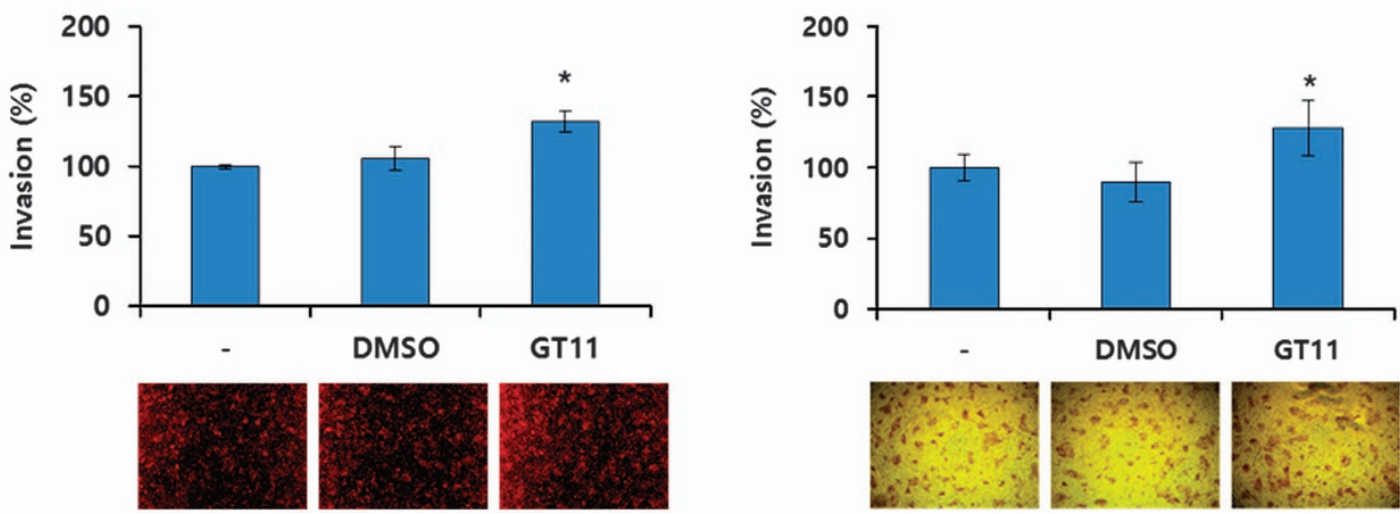

Figure 3 A 1:1 mixture of glycitin and TMF increases invasive ability of dermal fibroblasts and HeCaT cells in co-culture conditions

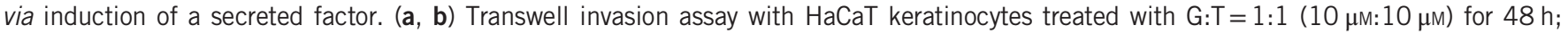
$7 \times 10^{4}$ cells per well were seeded on the insert, and dermal fibroblasts were also seeded on bottom for co-culture. Invasive ability was measured as described in the 'Materials and methods' section and is quantified in b. (c, d) Transwell invasion assay with dermal fibroblasts treated with G:T=1:1 $(10 \mu \mathrm{m}: 10 \mu \mathrm{m})$ for $48 \mathrm{~h} ; 7 \times 10^{4}$ cells per well were seeded on the insert, and HeCaT keratinocytes were also seeded on bottom for co-culture. Invasive ability was measured as described in the 'Materials and methods' section and is quantified in d. (e) Diagram illustrating the direct co-culture system utilized for the invasion assays. Arrows indicate HaCaT keratinocytes, and arrowheads indicate dermal fibroblasts. (f) Invasion assay with $\mathrm{HaCaT}$ keratinocytes and dermal fibroblasts in direct contact, using HaCaT keratinocytes transfected with a vector expressing the mCherry fluorescent protein. Invasive ability was measured as described in the 'Materials and methods' section. ${ }^{*} P<0.05$ as compared with control, ${ }^{* *} P<0.001$ as compared with control, G: glycitin, T: TMF. 
(Supplementary Data 2). Therefore, we hypothesized that this protein might function as a secreted factor that mediates the interaction between keratinocytes and fibroblasts. To test this, we collected medium from co-cultured cells post treatment and measured the expression of mature TGF- $\beta 1$ protein using western blot analysis. TGF- $\beta 1$ was detected in all co-culture media and was significantly increased in supernatant from cells treated with $\mathrm{G}: \mathrm{T}=1: 1$, but not those stimulated with either $\mathrm{G}: \mathrm{T}=1: 2$ or $\mathrm{G}: \mathrm{T}=2: 1$ (Figure $4 \mathrm{~b}$ ). We also found that TGF- $\beta 1$ mRNA transcript levels were increased in both $\mathrm{HaCaT}$ keratinocytes and fibroblasts from co-culture assays (Figure 4c). When tested during skin cell migration,

a
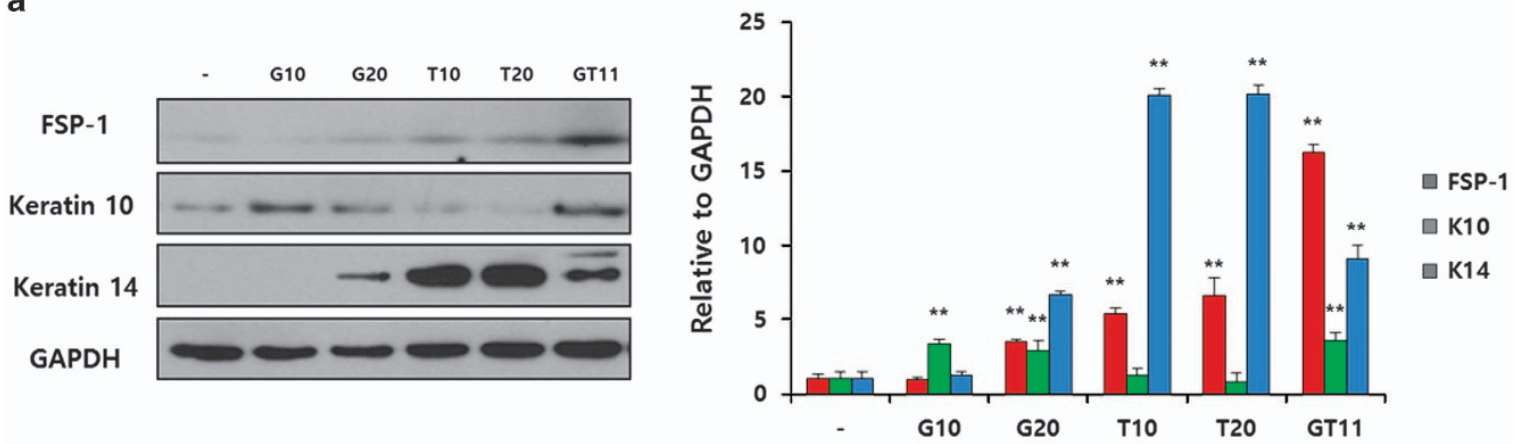

b
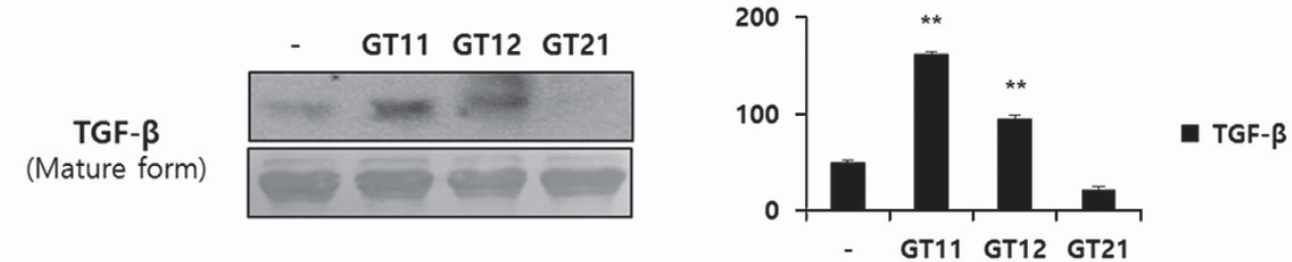

C

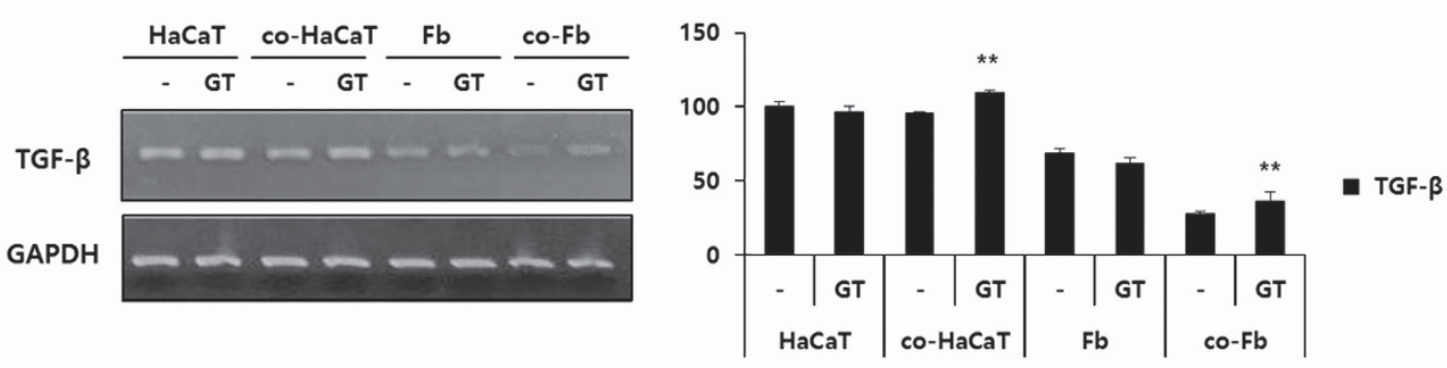

d
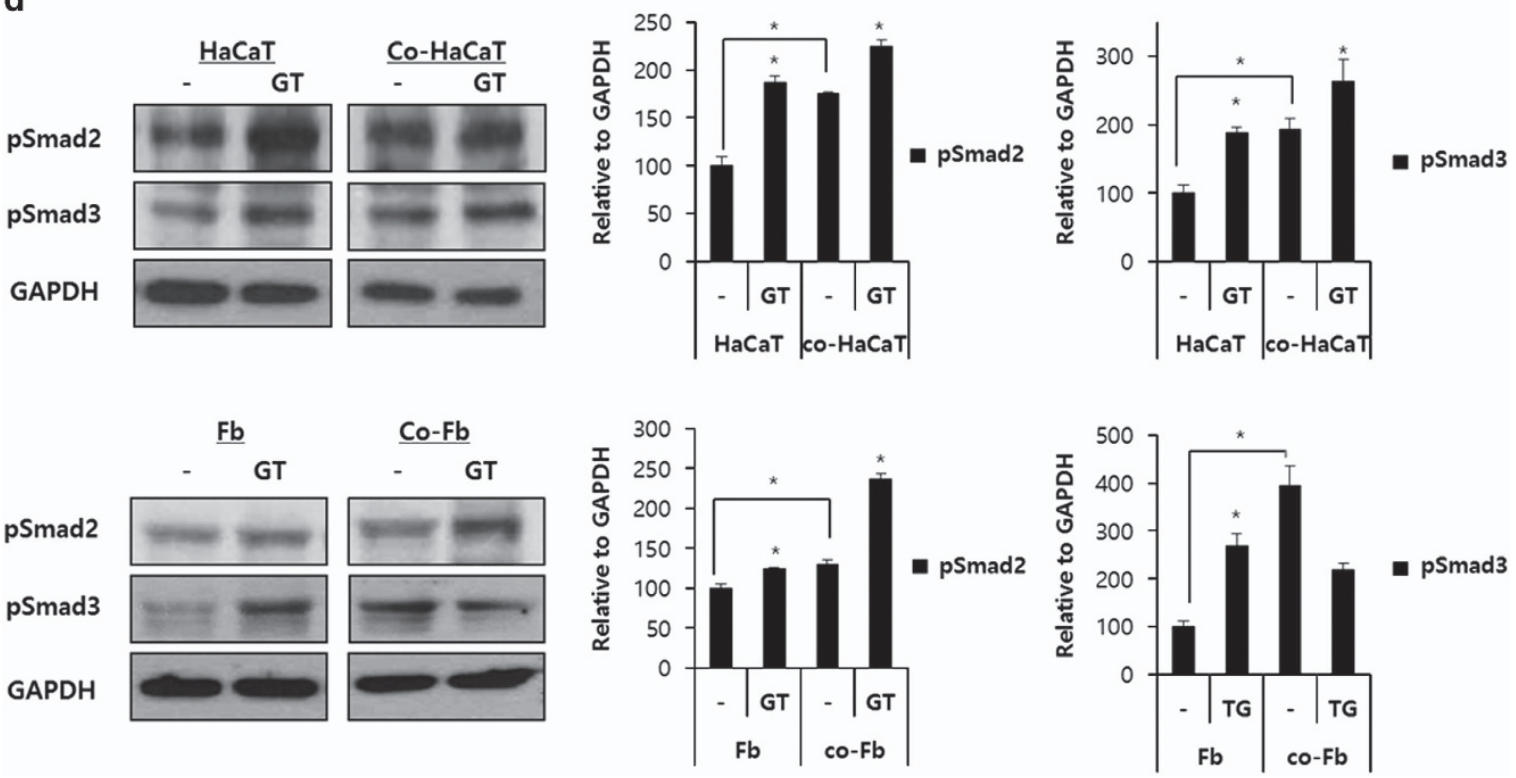
no changes in the levels of TGF- $\beta$ 2, 3 and KGF were observed (data not shown). The results suggest that keratinocytes and fibroblasts secrete TGF- $\beta$ 1 as a major mediator when stimulated by glycitin and TMF at a 1:1 ratio. To clarify whether TGF- $\beta 1$ affects keratinocytes and fibroblasts, we examined the expression of $\operatorname{Smad} 2 / 3$, which is downstream of the TGF- $\beta$ pathway. The phosphorylation of Smad2/3 was significantly increased in co-cultured cells compared with single-cultured cells; it was activated more so by TMF and glycitin treatment, but not by Smad3 in fibroblasts (Figure 4d).

From these experiments, we demonstrate that co-treatment with glycitin and TMF likely promotes interaction between keratinocytes and fibroblasts via the secretion of TGF- $\beta$ and promotes functions in both the epidermis and dermis related to wound repair.

\section{Co-treatment with TMF and glycitin accelerates wound closure and collagen synthesis}

To further verify that co-treatment with glycitin and TMF can promote wound healing, we assessed the effects of these compounds in an in vivo excision assay using ICR mice. We first made excisional wounds on the back using a $5 \mathrm{~mm}$ diameter punch. Glycitin and TMF were mixed in a 1:1 ratio $(200 \mu \mathrm{m}$ each) in butylene glycol, and wound sites were treated with $200 \mu \mathrm{l}$ of this mixture once a day, for 2 weeks. As a positive control, wounds were treated with Madecassol, a healing ointment made from an extract of the medicinal herb, Centella asiatica, which contains antibiotic and anti-inflammatory properties. It has been shown to promote collagen synthesis and regeneration and to prevent scar formation. Fucidin, an anti-infective ointment that contains the fusidic acid, was also utilized as a positive control. We observed that mice treated with G:T $=1: 1$ showed faster wound closure, as compared with the Madecassol and Fucidin groups (Figure 5a and b). These data are consistent with previous results, demonstrating that these compounds are most effective when used in a 1:1 ratio.

In addition, hematoxylin/eosin staining showed that combined treatment with glycitin and TMF effectively promoted the development of specialized appendages in the wound site, including hair follicles and sweat glands, which showed morphologies similar to those in normal skin (Figure 5c). Skin damage in the combined treatment group was also ameliorated, as evidenced by small scar width (Figure 5d) and relatively thin epidermis (Figure 5e). Collagen deposition was observed through Masson's trichrome staining (Figure $5 \mathrm{c}$ and f), and Ki67-positive cells, which indicate proliferation, were present in the basal layer of the epidermis, as well as the adnexa (Data not shown), exclusively in glycitin and TMF group. These results clearly demonstrate the ability of combined glycitin and TMF treatment to promote wound healing.

\section{Co-treatment with TMF and glycitin promotes reorganization and inhibits wound fibrosis}

We next assessed the effectiveness of glycitin/TMF treatment to prevent scarring using a murine burn wound model. Burns were made by searing the dorsal skin of C57BL/6 mice with a hot iron. These wounds were then treated using the same conditions as described for the excision wound model, except in this case, burns were treated for 8 weeks. As predicted, we observed that burns treated with the glycitin/TMF mixture showed faster healing than the other groups (Figure 6a). After 8 weeks, we checked hair growth in the scar area, since this can indicate remodeling of skin, and found that the glycitin/TMF-treated group showed the most hair growth (Figure 6b). We then removed the hair over the burn site and measured the size of the scars; we found that scars treated with glycitin/TMF were significantly reduced, as compared with those treated with the DMSO control (Figure $6 \mathrm{c}$ and d). Specifically, whereas the scars from the positive controls and DMSO-treated groups showed thickened epidermis and excessive collagen deposition, both epidermal thickness and collagen deposition were reduced in the TMF and glycitin/TMF co-treated groups (Figure 6e-h). The glycitin/TMF co-treated group, in particular, showed improved regeneration of appendages and a fully formed panniculus (Figure 6e-f). Because glycitin has no effect on re-epithelialization and contributes to the synthesis of collagen, we excluded the group treated with glycitin only in the burn wound experiment.

Since TGF- $\beta$ is highly expressed in fibroblasts derived from hypertrophic scars and in scar tissue, ${ }^{20}$ we collected scar tissues after 4 and 8 weeks of drug treatment and analyzed TGF- $\beta$ expression in tissue using western blot. We found that the amount of TGF- $\beta$ in glycitin/TMF-treated scars was significantly decreased, as compared with controls, with

Figure 4 Co-treatment with glycitin and TMF promotes differentiation and proliferation in co-culture condition via secretion of TGF- $\beta$. (a) HaCaT keratinocyte and dermal fibroblast cells $\left(1 \times 10^{5}\right.$ each) were seeded on $100 \mathrm{~mm}$ cell culture dishes and incubated for $24 \mathrm{~h}$. Protein lysates from cells treated with glycitin (G-10 $\mu \mathrm{m}$ and G-20 $\mu \mathrm{m})$, TMF (T-10 $\mu \mathrm{m}$ and T-20 $\mu \mathrm{m})$ or G:T=1:1 (10 $\mu \mathrm{M}: 10 \mu \mathrm{M})$ were obtained using RIPA solution, and proteins were resolved by $10 \%$ sodium dodecyl sulfate-polyacrylamide gel electrophoresis. Western blot to measure the expression of differentiation and proliferation-related factors was performed, and in all cases, expression levels were normalized to GAPDH. (b) Western blot assay to detect TFG- $\beta$ expression in conditioned media from co-cultured cells treated with $\mathrm{G}: T=1: 1 \quad(10 \mu \mathrm{m}: 10 \mu \mathrm{m}), \mathrm{G}: \mathrm{T}=1: 2 \quad(6.7 \mu \mathrm{m}: 13.3 \mu \mathrm{m})$ and $\mathrm{G}: \mathrm{T}=2: 1 \quad(13.3 \mu \mathrm{m}: 6.7 \mu \mathrm{m})$ for $24 \mathrm{~h}$. TGF- $\beta$ expression was measured by comparing with ponceuS. (c) RT-PCR to measure TGF- $\beta$ transcript levels in co-cultured cells from transwell assays; TGF- $\beta$ expression levels were normalized to GAPDH. (d) Western blot assay to detect phospho-Smad2 and phosphor-Smad3 in cell lysates from single-cultured and co-cultured cells after $24 \mathrm{~h}$. ${ }^{*} P<0.05$ as compared with control, ${ }^{*} P<0.001$ as compared with control, G: glycitin, T: TMF. TMF, 4',6,7-trimethoxyisoflavone; TGF- $\beta$, transforming growth factor-beta. 
a

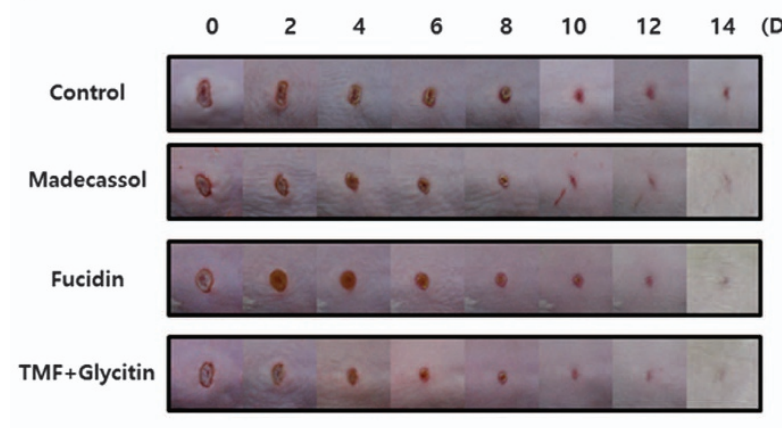

b

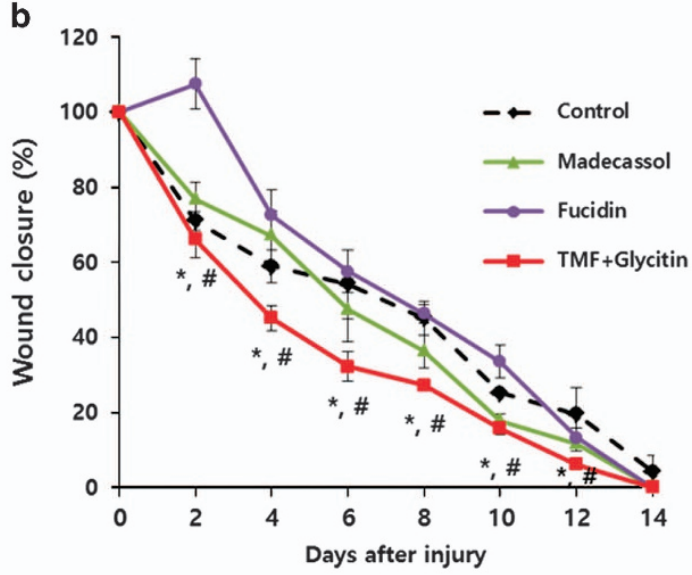

C Normal tissue

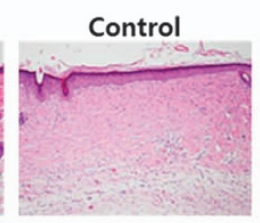

Madecassol

Fucidin

TMF+Glycitin

H/E

stain

(X100)
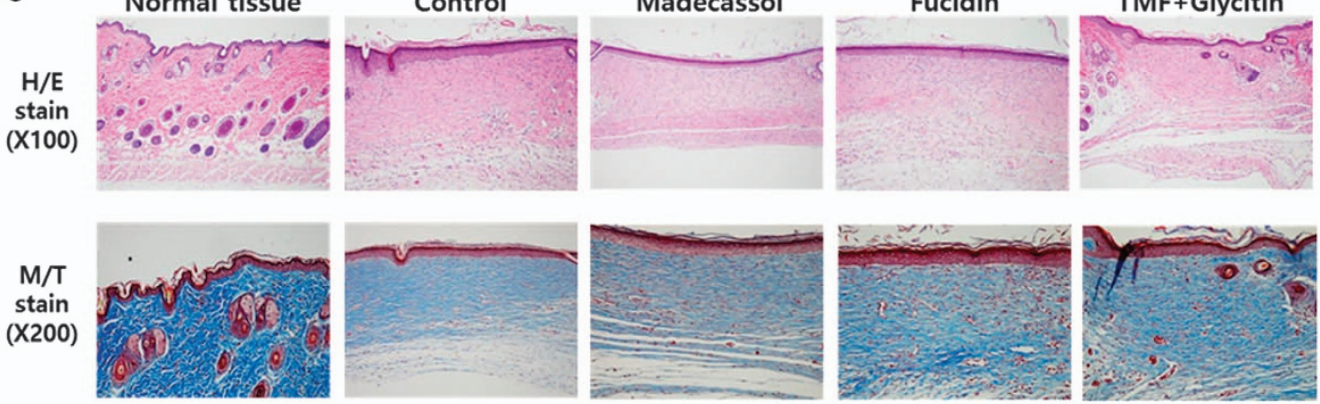

d
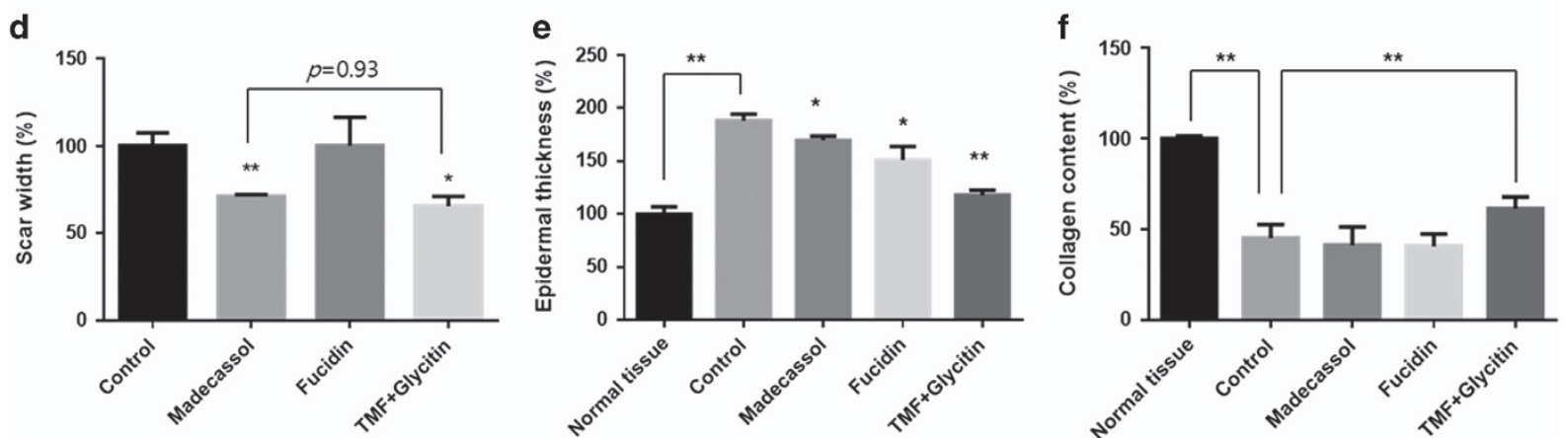

Figure 5 A 1:1 mixture of glycitin and TMF accelerates wound closure and protects against scar formation in an in vivo excisional wound model. (a, b) Wound closure in our excisional wound model after 2 weeks. Photographs were taken every 2 days, and wounds were measured using the Image J program. 'Control' indicates the butylene glycol; ${ }^{*} P<0.05$ as compared with Madecassol, $\# P<0.001$ as compared with Fucidin. (c) On the last day of treatment, skin tissues were isolated, fixed and stained with hematoxylin/eosin and Masson's trichrome. (d) Scar width, (e) epidermal thickness and (f) collagen content were measured 14 days after wounding using the Image J program. TMF, 4',6,7-trimethoxyisoflavone.

samples isolated at 4 (Figure 6i) and 8 weeks (Figure 6j) showing a similar trend. These observations suggest that co-treatment with glycitin and TMF can promote wound healing and prevent scarring in an in vivo skin wound animal model.

\section{DISCUSSION}

In this paper, we present evidence that treatment with glycitin and TMF can promote wound healing in vitro and in vivo, and a one-to-one ratio of these two compounds exerts synergistic effects on keratinocytes and fibroblasts that are mediated, at least in part, by secreted TGF- $\beta$.
Isoflavones are phytoestrogen compounds that are found in legumes, such as the soybean and kudzu vine. ${ }^{21}$ In soybeans, these can be present in one of three aglycon forms, known as such as daizein, genistein and glycitein, or in the corresponding glycoside forms, referred to as daidzine, genistin and glycitin, respectively. ${ }^{22}$ Whereas the glycosides are abundant in non-fermented soybean food, the aglycon forms are highly enriched in fermented food. ${ }^{23}$ In any soy-based food, the specific isoflavone content is dependent on the type of soybean, the processing method, and the potential addition of other foods. ${ }^{24}$ Critically, isoflavones have demonstrated many health benefits and are thought to reduce the risk of 


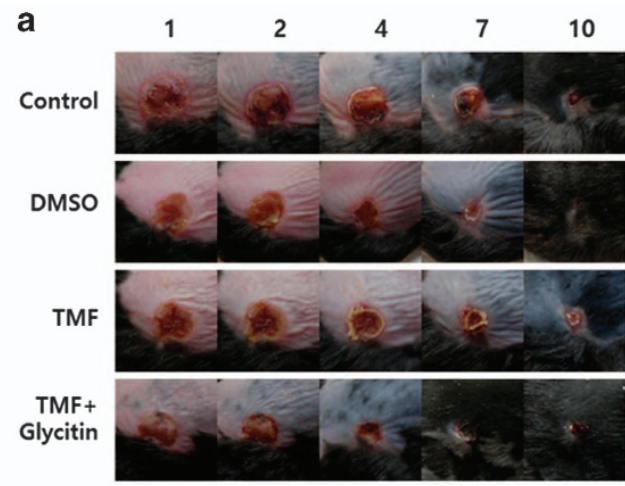

C

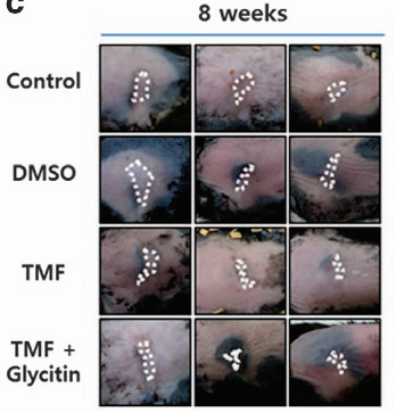

e

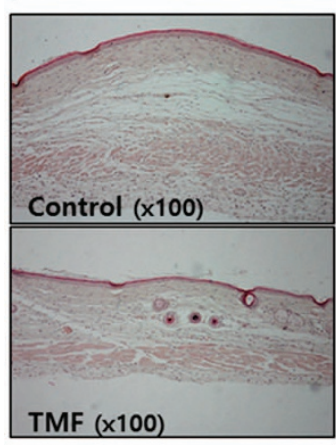

g
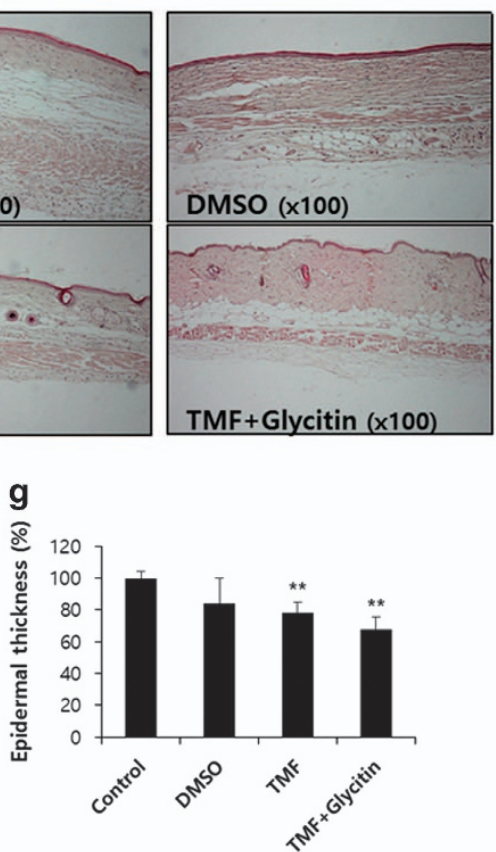

b

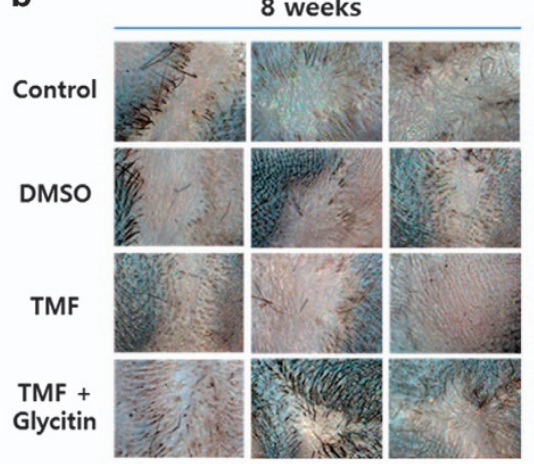

d

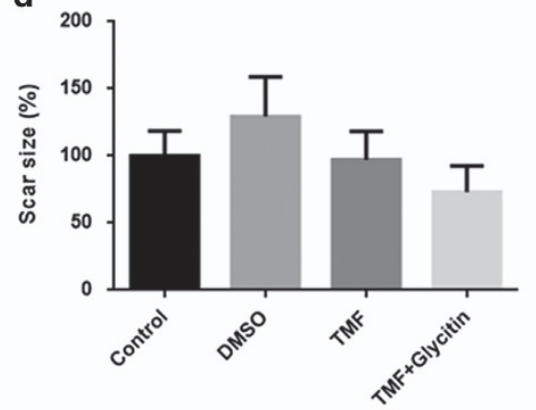

f
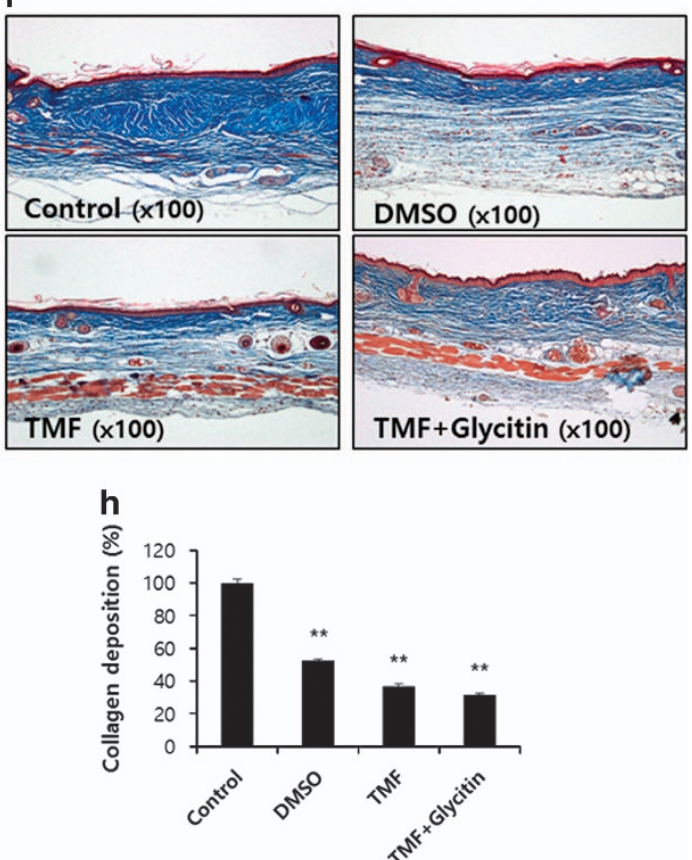

Figure 6 A 1:1 mixture of glycitin and TMF reduces scarring an in vivo burn wound model. (a) Burn wound closure after treatment for 10 days. (b) Wound sites were treated every day for 8 weeks; hair was then removed, and the scars were photographed using a digital camera or (c) the skin testing machine. (d) Scar size was measured 8 weeks after wounding using the Image J program. (e-h) Skin tissues were isolated, fixed and stained with both hematoxylin/eosin and Masson's trichrome. Epidermal thickness and collagen content were measured using the Image J program. (i) Western blot analysis of skin tissue isolated from wound sites 4 weeks and (j) 8 weeks after wounding. ${ }^{*} P<0.05$ as compared with control, ${ }^{* *} P<0.001$ as compared with control, G: glycitin, T: TMF. TMF, 4',6,7-trimethoxyisoflavone. 
i

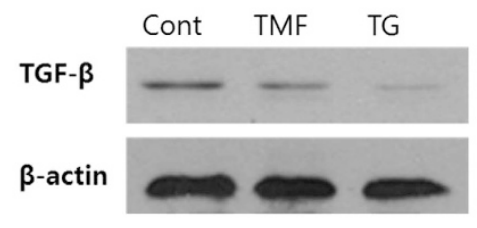

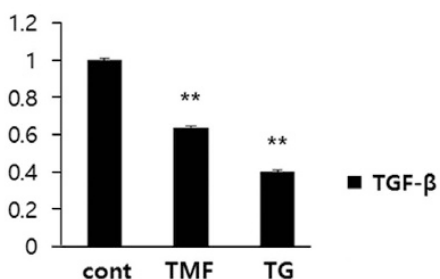

j
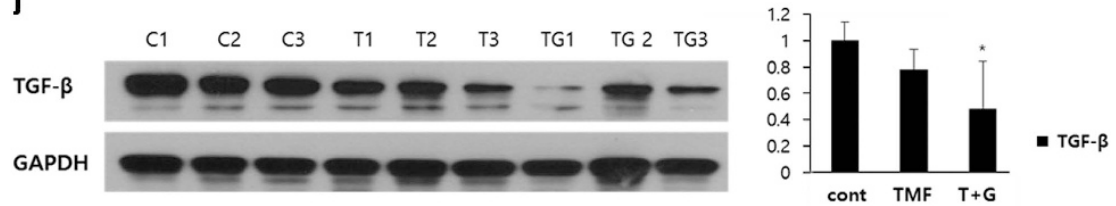

Figure 6 Continued.

hormone-related disease risk and protect against harmful elements such as UV radiation. ${ }^{25}$ For example, genistein and daidzein can prevent osteoporosis by increasing bone mineral content and density and by stimulating the formation of bone tissue. ${ }^{26}$ The antioxidant properties of isoflavones are also believed to protect against atherosclerosis, which is characterized by oxidation of the low density lipoprotein component of cholesterol that blocks the blood flow. ${ }^{27}$ Isoflavones can further activate estrogen receptors in the vagina, ovum and lacteal gland by mimicking estrogens or functioning as anti-estrogens, ${ }^{28}$ and these have been shown to have an antioxidant ability, similar to vitamin E/C. ${ }^{29}$ Among the isoflavones, genistein in particular, can reduce cancer cell viability by inhibiting angiogenesis, which effectively starves the cells of oxygen and nutrients. ${ }^{30}$

We have previously found that treatment with the soy isoflavone, glycitin, could promote fibroblast cell proliferation and migration but had no effect on keratinocytes. Conversely treatment with the amphiisoflavone-derivative, TMF, could induce the migration of keratinocytes, but not fibroblasts. Because the proliferation and migration of both keratinocytes and dermal fibroblasts are critical for effective skin wound repair, we tested the effect of a combined glycitin-TMF treatment on these cell types in a co-culture system and in two mouse models for skin repair.

Keratinocytes and dermal fibroblasts interact closely with one another, and they require cell-cell interactions to produce a cellular environment conducive to wound repair. ${ }^{31}$ Critically, it has been shown that co-culturing keratinocytes in the presence of fibroblasts has profound effects on epithelial reorganization and differentiation, which differ from what is observed when keratinocytes are cultured either alone or with few fibroblast cells. ${ }^{32}$ This epidermal reorganization appears to be mediated by a diffusible factor, as well as specific cellular matrix interactions that occur via the integrin pathway. ${ }^{33}$ As the major cell-type that is located adjacent to epidermis, fibroblasts synthesize ECM components and are also capable of secreting factor to modulate the proliferation, migration and differentiation of other cells, especially keratinocytes. ${ }^{34}$

Here, we found that when keratinocytes and fibroblasts are cultured such that they do not contact one another but share medium, the invasive ability of fibroblasts remarkably increased by ten times, whereas migration was unaffected (Figures 2 and 4). Notably, under these same conditions, the proliferation, migration and invasion of keratinocytes were all elevated, as compared with controls (Figures 3 and 4). Myofibroblasts are the activated form of dermal fibroblasts and are characterized by mesenchymal features. These cells secrete ECM-degrading enzymes, known as MMPs, and display increased viability and invasion. ${ }^{35}$ Myofibroblasts are activated by tumor necrosis factor (TNF)- $\alpha$, express the TNF-RI and TNF-RII receptors, ${ }^{36}$ and can induce proliferation, invasion and MMP-9 secretion. ${ }^{37}$ Stromal myofibroblasts also form during cancer development and can drive invasive cancer growth. ${ }^{38}$ In Figure 5a, we demonstrate that treatment with a mixture containing a 1:1 ratio of glycitin and TMF can induce expression of FSP1 in co-cultured cells, suggesting that this treatment can promote the activation and differentiation of fibroblasts.

The epidermal barrier protects against toxins, pathogens and moisture loss. ${ }^{39}$ During epidermis development, basal keratinocytes either differentiate or migrate, to become suprabasal keratinocytes (spinous layer, granular layer) or divide disproportionally to produce proliferative cells, which remain in the basal layer. ${ }^{40}$ The NF-KB, Notch, C/EBP and MAPK signaling pathways are known to be involved in epidermal differentiation and barrier restoration. ${ }^{39}$ Critically, we show that treatment with a 1:1 mixture of glycitin and TMF can promote keratinocyte differentiation, as evidenced by elevated KRT10 protein expression, and keratinocyte proliferation is correspondingly attenuated in response to this (Figure 5). These data suggest that glycitin and TMF can induce keratinocyte differentiation, and can modulate the proliferation and migration of both cell types.

Wound healing is a complex process that is aimed at restoring tissue integrity. ${ }^{41}$ Several cell and tissue 
types, including keratinocytes, fibroblasts, blood vessels, macrophages and neutrophils are involved in this process and communicate with one another via circulating secreted factors. ${ }^{16}$ Sander W. Spiekstra investigated the factors secreted from epidermal keratinocytes and dermal fibroblasts, using full-skin, as well as epidermal and dermal substitutes. Whereas the full-skin substitute produced numerous inflammatory and angiogenic factors, such interleukin (IL)-6, chemokine (C-X-C motif) ligand 8 (CXCL8 or IL-8) and CC chemokine ligands (CCLs), the epidermis and dermis produced these proteins but in lower amounts. The epidermal substitute, in particular, was found to secrete IL-1, TNF- $\alpha$, PDGF and TGF- $\beta 1,-\beta 2$ and $-\beta 3$, which act synergistically to mediate wound healing with factors secreted from the dermal substitute, such as TGF- $\beta 1$, fibroblast growth factor (FGF)-2 and keratinocyte growth factor (KGF)..$^{42}$

The prevention of scarring after wound healing requires a lengthy period of medical intervention to reduce disfigurement, discomfort and disability. ${ }^{43}$ Hypertrophic scars are fibrotic lesions containing myofibroblasts that express $\alpha$-SMA, collagen and other ECM components, ${ }^{44}$ and these commonly form after injuries, such as burns, delayed epithelialization, or secondary damage. ${ }^{45}$ The cytokine TGF- $\beta$, in particular, is responsible for fibrotic scarring. ${ }^{20}$ During TGF- $\beta$ pathway-mediated hypertrophic scar formation, there is an up-regulation of SMAD-2 and SMAD-3, as well as increased expression of TGF- $\beta 1$, T $\beta R I$ and T $\beta R I I$, which lead to positive feedback loop. ${ }^{46}$ As a result, connective tissue growth factor (CTGF), a known downstream mediator of TGF- $\beta$, induces proliferation of myofibroblasts and expression of collagen types I and III. ${ }^{47}$ Sisco et al. ${ }^{48}$ reported that inhibition of CTGF activity limited hypertrophic scarring via the suppression of myofibroblasts, collagen and tissue inhibitor of metalloproteinase (TIMP)-1 expression. The repression of apoptosis, mechanobiology, angiogenesis, and inflammatory responses can also contribute to a reduction in scarring. For example, increased levels of Bcl-2 and tissue transglutaminase, lead to decreased Fas, and p53 alteration inhibits apoptosis in hypertrophic scar-derived myofibroblasts. Further, mechanical tension can upregulate expression of genes related to matrix remodeling but not apoptosis genes, and when the angiopoietin1/angiopoietin2 ratio is decreased, microvessel density is increased in hypertrophic scars. In hypertrophicderived fibroblasts, expression of IL-6, IL-8, TLR-4 and MCP-1 was increased, as well as MMPs and TIMPs. ${ }^{46}$ All of these pathways contribute to the excessive deposition of myofibroblasts and matrix components, leading to scar formation. TGF- $\beta$ has diverse roles depending on the phase of cutaneous wound healing. ${ }^{49}$ In particular, it differentially acts on re-epithelialization and scarring. For example, increased expression of TGF- $\beta$ induces re-epithelialization and contraction, whereas reduced expression of TGF- $\beta$ contributes to reduced scarring. Collagen deposition is controlled by skin cells stimulated by TGF- $\beta$. During re-epithelialization, the dermis needs matrix proteins such as collagen to restore structure and replace granulation tissue, but during the maturation process, collagen deposition results in scar tissue formation. Thus, the balance of collagen regulated by TGF- $\beta$ is important during the wound healing process. The 'good' wound healing can indicate faster wound closure or less scarring. We found that co-treatment with glycitin and TMF promotes TGF- $\beta$ expression, reorganization and fibroblast differentiation in normal wound model, whereas it decreases TGF- $\beta$ and scar size in the impaired burn wound model.

In this study, we show that glycitin and TMF act synergistically to promote epidermal regeneration and dermal activation. Specifically, treatment with these compounds influences the interaction between keratinocytes and fibroblasts to promote wound repair in vitro and in vivo, and TGF- $\beta$ functions as a 'critical mediator' for this response. Furthermore, long-term treatment helps to decrease scar size after burn injury by degrading matrix components, such as collagen, in a mouse burn wound model. In conclusion, our data suggest that glycitin and TMF act together on keratinocytes and fibroblasts to induce wound healing and scar reduction via the release of TGF- $\beta$. We further suggest that these compounds may hold therapeutic potential for the development of improved treatments for cutaneous injury.

\section{CONFLICT OF INTEREST}

The authors declare no conflict of interest.

\section{ACKNOWLEDGEMENTS}

This work was supported by a grant from the Next-Generation BioGreen 21 program (No. PJ011303012016) funded by the Rural Development Administration, Republic of Korea.

1 Harborne JB, Williams CA. Advances in flavonoid research since 1992. Phytochemistry 2000; 55: 481-504.

2 Pietta PG. Flavonoids as antioxidants. J Nat Prod 2000; 63: 1035-1042.

3 Yao LH, Jiang YM, Shi J, Tomas-Barberan FA, Datta N, Singanusong R et al. Flavonoids in food and their health benefits. Plant Food Hum Nutr 2004; 59: 113-122.

4 Lee CH, Yang L, Xu JZ, Yeung SYV, Huang Y, Chen ZY. Relative antioxidant activity of soybean isoflavone and their glycosides. Food Chem 2005; 90: 735-741.

5 Song TT, Hendrich S, Murphy PA. Estrogenic activity of glycitein, a soy isoflavone. J Agric Food Chem 1999; 47: 1607-1610.

6 Zielonka J, Gebicki J, Grynkiewicz G. Radical scavenging properties of genistein. Free Radic Biol Med 2003; 35: 958-965.

7 Seo GY, Huh JS, Cho M. The protective effect of glycitin on UV-induced skin photoaging in human primary dermal fibroblast. J Korean Soc App/ Biol Chem 2014; 57: 463-478.

8 Kim YM, Huh JS, Lim Y, Cho M. Soy isoflavone glycitin (4'-hydroxy-6methoxyisoflavone-7-D-glucoside) promotes human dermal fibroblast cell proliferation and migration via TGF-beta signaling. Phytother Res 2015; 29: 757-769.

9 Saah EF, Sielinou VT, Kuete V, Lacmata ST, Nkengfack AE. Antimicrobial and antioxidant isoflavonoid derivatives from the roots of Amphimas pterocarpoides. Z Naturforsch B J Chem Sci 2013; 68: 931-938.

10 Bui NT, Ho MT, Kim YM, Lim Y, Cho M. Flavonoids promoting HaCaT migration: II. Molecular mechanism of 4',6,7-trimethoxyisoflavone via NOX2 activation. Phytomedicine 2014; 21: 570-577.

11 Stadelmann WK, Digenis AG, Tobin GR. Physiology and healing dynamics of chronic cutaneous wounds. Am J Surg 1998; 176: 26S-38S. 
12 Wang Z, Wang Y, Farhangfar F, Zimmer M, Zhang Y. Enhanced keratinocyte proliferation and migration in co-culture with fibroblasts. PLOS ONE 2012 ; 7: e40951.

13 Pakyari M, Farrokhi A, Maharlooei MK, Ghahary A. Critical role of transforming growth factor beta in different phases of wound healing. Adv Wound Care 2013; 2: 215-224.

14 Zhang Y, Lin Z, Foolen J, Schoen I, Santoro A, Zenobi-Wong M et al. Disentangling the multifactorial contributions of fibronectin, collagen and cyclic strain on MMP expression and extracellular matrix remodeling by fibroblasts. Matrix Biol 2014; 40: 62-72.

15 Shephard P, Hinz B, Smola-Hess S, Meister JJ, Krieg T, Smola H. Dissecting the roles of endothelin, TGF-beta and GM-CSF on myofibroblast differentiation by keratinocytes. Thromb Haemost 2004; 92: 262-274.

16 Stroncek JD, Reichert WM. Overview of wound healing in different tissue types. In: Reichert WM (ed.). Indwelling Neural Implants: Strategies for Contending with the In Vivo Environment. CRC press/Taylor\&Francis: Boca Raton, FL, USA, 2008, pp 5-9.

17 Yates CC, Hebda P, Wells A. Skin wound healing and scarring: fetal wounds and regenerative restitution. Birth Defects Res C Embryo Today 2012; 96: 325-333.

18 Lu SW, Zhang XM, Luo HM, Fu YC, Xu MY, Tang SJ. Clodronate liposomes reduce excessive scar formation in a mouse model of burn injury by reducing collagen deposition and TGF-betal expression. Mol Biol Rep 2014; 41: 2143-2149.

19 Wang Z, Liu X, Zhang D, Wang X, Zhao F, Shi P et al. Coculture with human fetal epidermal keratinocytes promotes proliferation and migration of human fetal and adult dermal fibroblasts. Mol Med Rep 2015; 11 : $1105-1110$

20 Leask A, Abraham DJ. TGF-beta signaling and the fibrotic response. FASEB J 2004; 18: 816-827.

21 Liu GY. Isolation, sequence identification, and tissue expression profile of 3 novel porcine genes: NCF2, BCKDHB and BCKDHA. J App/ Genet 2009; 50: 47-50.

22 Sepehr E, Cooke GM, Robertson P, Gilani GS. Effect of glycosidation of isoflavones on their bioavailability and pharmacokinetics in aged male rats. Mol Nutr Food Res 2009; 53: S16-S26.

23 Zubik L, Meydani M. Bioavailability of soybean isoflavones from aglycone and glucoside forms in American women. Am J Clin Nutr 2003; 77: $1459-1465$.

24 Donya A, Hettiarachchy N, Liyanage R, Lay J Jr, Chen P, Jalaluddin M. Effects of processing methods on the proximate composition and momordicosides $\mathrm{K}$ and $\mathrm{L}$ content of bitter melon vegetable. J Agric Food Chem 2007; 55: 5827-5833.

25 Larkin T PW, Astheimer L. The key importance of soy isoflavone bioavailability to understanding health benefits. Crit Rev Food Sci Nutr 2008; 48: 538-552.

26 Zheng X LS, Chun OK. Soy isoflavones and osteoporotic bone loss: a review with an emphasis on modulation of bone remodeling. J Med Food 2016; 19: 1-14.

27 Kalaiselvan V, Kalaivani M, Vijayakumar A, Sureshkumar K Venkateskumar K. Current knowledge and future direction of research on soy isoflavones as a therapeutic agents. Pharmacogn Rev 2010; 4: 111-117.

28 Patisaul HB, Jefferson W. The pros and cons of phytoestrogens. Front Neuroendocrinol 2010; 31: 400-419.

29 Yoon GA, Park S. Antioxidant action of soy isoflavones on oxidative stress and antioxidant enzyme activities in exercised rats. Nutr Res Pract 2014; 8: 618-624.

30 Lee JY, Kim HS, Song YS. Genistein as a potential anticancer agent against ovarian cancer. J Tradit Complement Med 2012; 2: 96-104.

31 Pastar I, Stojadinovic O, Yin NC, Ramirez H, Nusbaum AG, Sawaya A et al. Epithelialization in wound healing: a comprehensive review. Adv Wound Care 2014; 3: 445-464.

32 Schoop VM, Mirancea N, Fusenig NE. Epidermal organization and differentiation of $\mathrm{HaCaT}$ keratinocytes in organotypic coculture with human dermal fibroblasts. J Invest Dermatol 1999; 112: 343-353.
33 Dipersio CM, Zheng R, Kenney J, Van De Water L. Integrin regulation of epidermal functions in wounds. Adv Wound Care 2014; 3: 229-246.

34 Cox TR, Erler JT. Remodeling and homeostasis of the extracellular matrix: implications for fibrotic diseases and cancer. Dis Model Mech 2011; 4: $165-178$.

35 Darby IA, Laverdet B, Bonte F, Desmouliere A. Fibroblasts and myofibroblasts in wound healing. Clin Cosmet Investig Dermatol 2014; 7: 301-311.

$36 \mathrm{He} \mathrm{J}$, Bazan HE. Synergistic effect of platelet-activating factor and tumor necrosis factor-alpha on corneal myofibroblast apoptosis. Invest Ophthalmol Vis Sci 2006; 47: 883-891.

37 Porter KE, Turner NA, O'Regan DJ, Ball SG. Tumor necrosis factor alpha induces human atrial myofibroblast proliferation, invasion and MMP-9 secretion: inhibition by simvastatin. Cardiovasc Res 2004; 64: 507-515.

38 Karagiannis GS, Poutahidis T, Erdman SE, Kirsch R, Riddell RH, Diamandis EP. Cancer-associated fibroblasts drive the progression of metastasis through both paracrine and mechanical pressure on cancer tissue. Mol Cancer Res 2012; 10: 1403-1418.

39 Wikramanayake TC, Stojadinovic 0, Tomic-Canic M. Epidermal differentiation in barrier maintenance and wound healing. Adv Wound Care 2014; 3: 272-280.

40 Usui ML, Mansbridge JN, Carter WG, Fujita M, Olerud JE. Keratinocyte migration, proliferation, and differentiation in chronic ulcers from patients with diabetes and normal wounds. J Histochem Cytochem 2008; 56: 687-696.

41 Borena BM, Martens A, Broeckx SY, Meyer E, Chiers K, Duchateau L et al. Regenerative skin wound healing in mammals: state-of-the-art on growth factor and stem cell based treatments. Cell Physiol Biochem 2015; 36: $1-23$.

42 Spiekstra SW, Breetveld M, Rustemeyer T, Scheper RJ, Gibbs S. Woundhealing factors secreted by epidermal keratinocytes and dermal fibroblasts in skin substitutes. Wound Repair Regen 2007; 15: 708-717.

43 Weed RO, Berens DE. Basics of burn injury: implications for case management and life care planning. Lippincotts Case Manag 2005; 10: 22-29.

44 Darby IA, Hewitson TD. Fibroblast differentiation in wound healing and fibrosis. Int Rev Cytol 2007; 257: 143-179.

45 Aarabi S, Longaker MT, Gurtner GC. Hypertrophic scar formation following burns and trauma: new approaches to treatment. PLoS Med 2007; 4: e234.

46 Penn JW, Grobbelaar AO, Rolfe KJ. The role of the TGF-beta family in wound healing, burns and scarring: a review. Int J Burns Trauma 2012; 2: 18-28.

$47 \mathrm{Lin} \mathrm{CH}, \mathrm{Yu} \mathrm{MC}$, Tung $\mathrm{WH}$, Chen TT, Yu CC, Weng CM et al. Connective tissue growth factor induces collagen I expression in human lung fibroblasts through the Rac1/MLK3/JNK/AP-1 pathway. Biochim Biophys Acta 2013; 1833: 2823-2833.

48 Sisco M, Kryger ZB, O'Shaughnessy KD, Kim PS, Schultz GS, Ding $X Z$ et al. Antisense inhibition of connective tissue growth factor (CTGF/CCN2) mRNA limits hypertrophic scarring without affecting wound healing in vivo. Wound Repair Regen 2008; 16: 661-673.

49 Beanes SR, Dang C, Soo C, Ting K. Skin repair and scar formation: the central role of TGF-beta. Expert Rev Mol Med 2003; 5: 1-22.

(c) (1) () $\Theta$ This work is licensed under a Creative Commons Attribution-NonCommercial-NoDerivs 4.0 International License. The images or other third party material in this article are included in the article's Creative Commons license, unless indicated otherwise in the credit line; if the material is not included under the Creative Commons license, users will need to obtain permission from the license holder to reproduce the material. To view a copy of this license, visit http://creativecommons.org/licenses/by-nc-nd/4.0/

Supplementary Information accompanies the paper on Experimental \& Molecular Medicine website (http://www.nature.com/emm) 